\title{
A WEIGHT BURETTE FOR THE MICROMEASUREMENT OF LIQUID VOLUMES
}

\author{
By Martin Shepherd
}

ABSTRACT

This paper describes a burette with which small volumes of liquid can be measured with an accuracy of 0.001 .cc. The burette is designed to make use of a modified weight burette principle. Mercury is used to displace the liquid to be measured, and this equivalent volume of mercury weighed to indirectly determine the volume of the displaced liquid.

The burette may be employed to measure liquids whose vapor pressures are low or not greatly in excess of atmospheric pressure at ordinary air temperatures. Data are given for its use with mixtures of the saturated hydrocarbons ranging in composition from butane to hexane and higher boiling members of the series.

A sketch, photograph, and complete description of the apparatus are given. Its operation is described in detail.

\section{CONTENTS}

I. Particular application necessitating the burette and its possible general application........ 287

II. Design of the burette . .

III. Detailed operation of the burette

IV. Results obtained with the burette..... 291

V. Summary _._. 292

\section{PARTICULAR APPLICATION NECESSITATING THE BU- RETTE AND ITS POSSIBLE GENERAL APPLICATION}

The determination of so-called gasoline in natural gas involved some experimental study of the separation of natural gases by fractional distillation at low temperatures and pressures. It was found impracticable, starting with a laboratory sample of 1 or 2 liters of gas, to carry the separation further than the isolation of butane, thus leaving pentane and heavier hydrocarbons in one fraction. The volume of this liquid residue was usually of the order of magnitude of 0.1 to $1.0 \mathrm{cc}$, depending on the composition and volume of the original sample. Its volume in the vapor phase was computed by totaling the volumes of butane, isobutane, propane, ethane, methane, nitrogen, oxygen, and helium, if any, all measured as gases, and subtracting from the volume of the sample. An average composition of the fraction containing pentane and higher homologues might be 
assumed from its density and vapor tension. The ratio between corresponding vapor and liquid volumes, ${ }^{1}$ together with the percentage composition of vapor in the sample, would then serve as a basis for the engineering computation of gallons of this particular fraction per million cubic feet of gas. In order to check this calculation, it was desirable to measure the liquid residue as such. Assuming that the fractional distillation was begun with a 1 liter sample of natural gas, this, in turn, required measurement of the pentane-plus residue with an accuracy of $0.001 \mathrm{cc}$, if an accuracy as great as 7 gallons per million cubic feet were to be attained in the engineering calculation.

A burette was designed which accomplished the measurement with this accuracy. The pentane and heavier hydrocarbons were condensed into the evacuated burette by subjecting a portion of the burette to liquid air temperatures. It is quite possible to use the burette in this manner for other liquids possessing suitable vapor pressures, provided they do not react with mercury, which is used as a confining fluid. It was because of this possible general application that the apparatus is here described.

\section{DESIGN OF THE BURETTE}

The principle of the burette is best understood if reference is made to the sketch. (Fig. 1.) The two bulbs 8 and 12 are accurately calibrated between the etch marks $7-10$ and $9-13$. The volume of 8 slightly exceeds that of 12, which in turn represents a slight excess over the maximum volume of liquid to be determined. These bulbs are immersed in a water bath, 16 , resting on the movable platform 18. The lower outlets of the bulbs are brought up over the edge of the water bath and thence down to two-way cock 14 and $Y$ cock 15. Mercury is supplied to the system from the auxiliary glass stoppered reservoir 4 and drained from the system through outlet 17 . The upper outlets of the bulbs and the reservoir terminate in two-way cocks 2,3 , and 5 . One outlet each of cocks 2 and 3 connects to a vacuum line 1 , into which is teed a line terminating in a fine needle valve 11 . One outlet 6 of the cock 5 is connected to the container holding the liquid to be measured. A second two-way cock (not shown) may be sealed onto the other outlet of cock 5 , providing a connection to either vacuum or air. This detail may be unnecessary if the burette is to be sealed in as an auxiliary unit of a larger apparatus; as, for example, a distillation or purifying system which contains the liquid to be measured and is already connected to a source of high vacuum.

1Anderson, R. P., J. Ind. Eng. Chem., 12, p. 852; 1920. 
The capillary leads interconnecting the bulbs and various cocks are $0.5 \mathrm{~mm}$ bore. Larger bores have a tendency to trap gas films where these connections $U$ over the top of the water jacket, thus breaking the siphon. Furthermore, adjustment of liquid menisci to

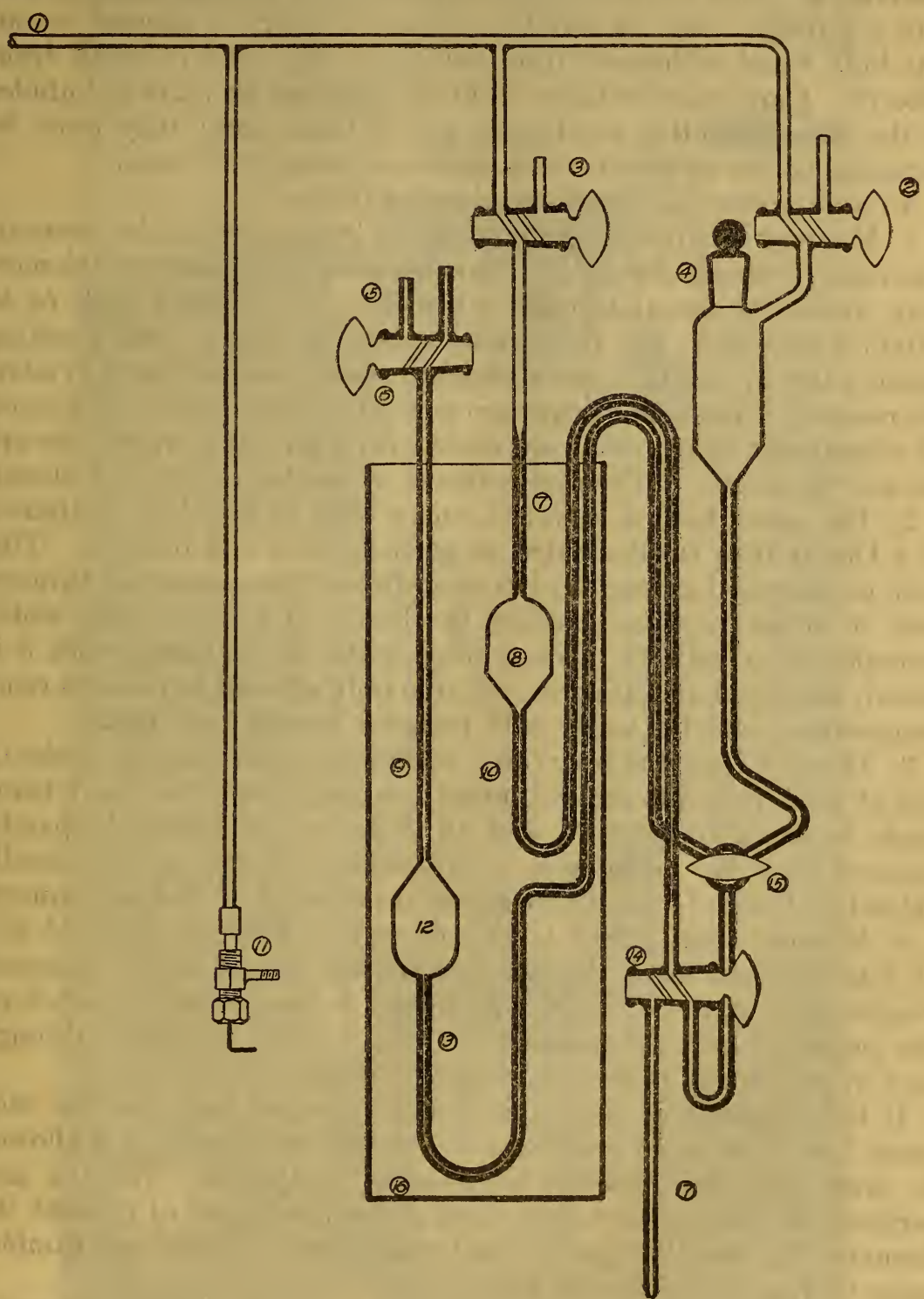

FIG. 1.-Diagram of burette

etch marks in a tube of such small diameter results in a high volumetric accuracy.

A photograph (fig. 2) of the apparatus serves to illustrate the details of construction of a typical unit. 


\section{DETAILED OPERATION OF THE BURETTE}

Before making a measurement the capillary leads connecting reservoir 4 and bulbs 8 and 12 are filled with mercury introduced at the reservoir 4. This is done by connecting 4 to 12 through cock 15 , and 4 to 8 through cocks 14 and 15 . Excess mercury is allowed to run into bulb 8 and withdrawn from thence through cock 14 to fill drain tube 17. Care must be taken to avoid trapping air films or bubbles in the interconnecting capillaries, and if these occur they must be displaced before an actual measurement of volume is made.

A liquid volume is then determined as follows:

1. Mercury is adjusted to etch mark 13 by connecting the reservoir 4 to bulb 12 through cock 15 . Final accurate adjustment of the mercury column to the etch mark is made by (a) cracking cock 15 to obtain a slow flow, and (b) turning cock 2 to vacuum and cracking needle valve 11 to admit just sufficient pressure to reservoir 4 to allow the mercury to creep slowly upward toward the etch mark. (This and all subsequent adjustments are made with a flow of mercury upward toward the mark.) When adjustment is reached, cock 15 is closed.

2. The water bath is removed, and a bath of liquid air contained in a Dewar tube is substituted to partially surround bulb 12. This bulb is evacuated as suggested previously and then connected through cock 5 to the reservoir holding the liquid to be measured, which recondenses in bulb 12. When the transfer is completed, cock 5 is closed, the liquid air bath removed, the bulb allowed to come to room temperature, and the water bath replaced around both bulbs.

3. Mercury from the reservoir 4 is allowed to flow through cocks 14 and 15 to fill bulb 8 to the etch mark 7 , adjustment at this mark being made by cracking cocks 14 and 15 in series and using the partial vacuum over the mercury in 4, which is regulated by the needle valve 11 . Cocks 14 and 15 are closed at the point of final adjustment.

4. Mercury from bulb 8 is allowed to flow through cocks 14 and 15 into bulb 12 until the meniscus of the liquid being measured reaches etch mark 9. Final adjustment is made exactly as before, the regulated reduced pressure in bulb 8 being admitted through cock 3 , with cocks 14 and 15 cracked in series.

If the meniscus of the liquid being measured overruns the etch mark 9 or if its vapor condenses above this etch mark, it is allowed to drain and the meniscus is properly readjusted. The $0.5 \mathrm{~mm}$ capillary is enlarged to $1.5 \mathrm{~mm}$ just above this mark, to prevent the formation of small slugs of condensed vapor, which are troublesome to draw back into the bulb.

It is, of course, evident that the vapor pressure of the liquid under investigation may require special spacing of bulb 8 with relation to bulb 12 , or that positive pressure may be required over the mercury in bulb 8. This factor determines the actual arrangement of the unit, and further limits the use of the apparatus to liquids which do not possess excessive vapor pressures, if measurements are to be 
Scientific Papers of the Bureau of Standards, Vol. 22

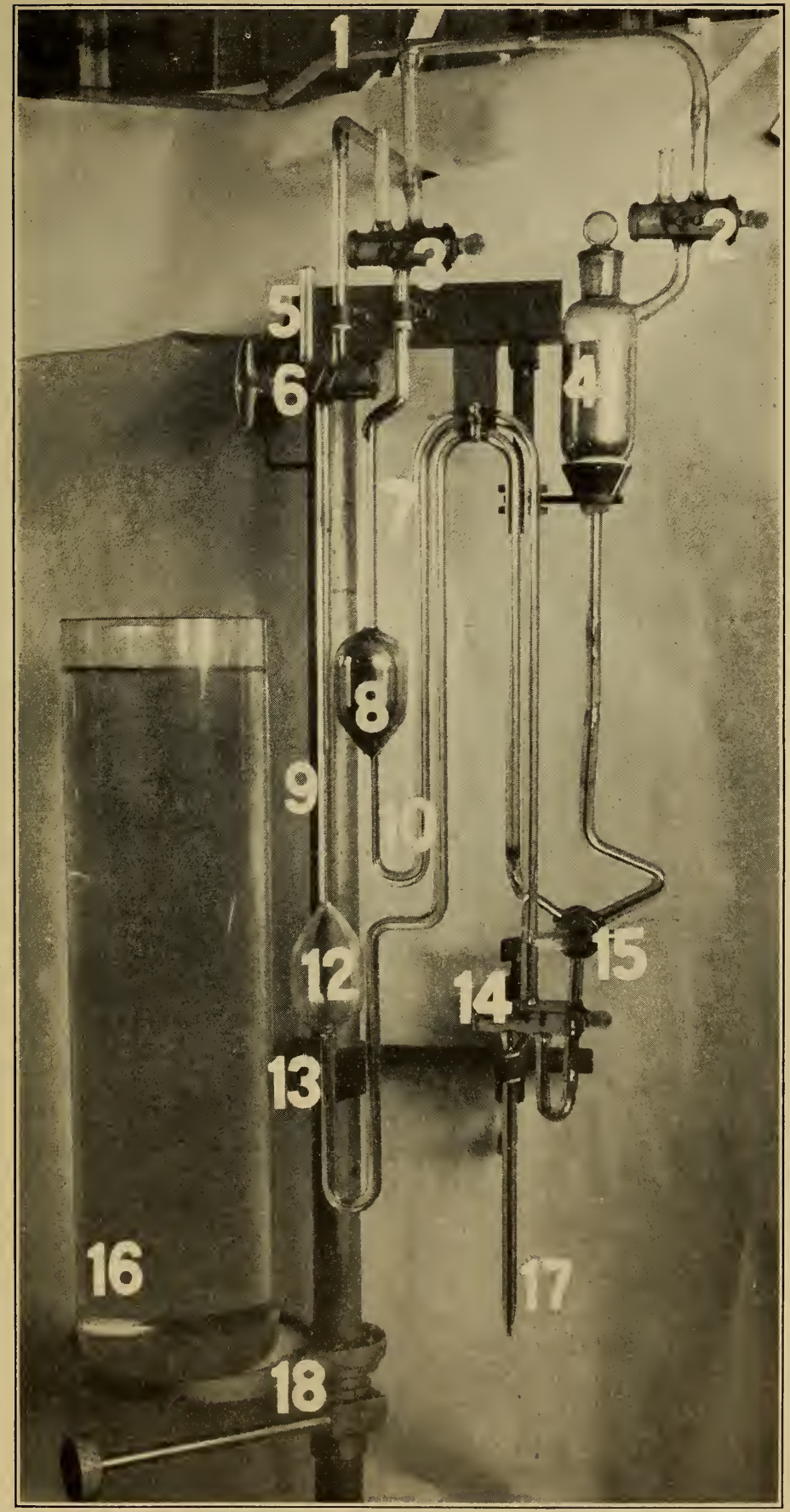

FIG. 2.-Burette assembly 
made at room temperatures. Lowering the bath temperature affords another control.

5. The mercury remaining in 8 is drained through cock 14 and drain $1^{77}$ into a weighing flask until etch mark 10 is reached. Drain 17 has previously been filled with mercury and its tip should be immersed in a dish of mercury which is withdrawn just before the weighing flask is placed to catch the measured drainage from bulb 8 . The tip 17 is then immersed in the outflowing mercury in the weighing flask, and if mark 10 is overrun mercury is redrawn into the burette from the flask by applying vacuum through cock 3. The final adjustment to mark 10 is made by regulating the pressure in 8 as before and cracking the lower stopcock 14 .

6. The mercury drained from 8 is weighed to $0.5 \mathrm{mg}$. The temperature of the water bath is observed ${ }^{2}$ and this weight corrected to the volume in cubic centimeters occupied at $20^{\circ} \mathrm{C} .{ }^{3}$ The volumes of 8 and 12 are known. The data are sufficient to calculate the volume of the liquid confined above the mercury in 12:

Volume of 8 -volume represented by weight of mercury remaining in 8 and drained therefrom for weighing=volume of mercury admitted to 12 .

Volume of 12 - volume of mercury admitted to $12=$ volume of liquid in 12 being measured.

This method may appear roundabout at first glance, but it effects the elimination of errors caused by wetting of the walls of 12 by the liquid to be measured, and the consequent impossibility of confining this liquid cleanly above the mercury in 12. This loss would result in appreciable error if a more direct measurement were used.

7. To prepare the burette for a second measurement the mercury should be slowly withdrawn from 12 into 8 , care being taken that no liquid confined on the bulb walls shall creep into the capillary lead below etch mark 13 when the mercury is withdrawn to this mark. The liquid may be pumped out of 12 by recondensation in the original reservoir at liquid-air temperatures or by evacuating with a suitable pump.

\section{RESULTS OBTAINED WITH THE BURETTE}

The results which can be obtained with the burette are indicated by three typical series of volume determinations recorded in the table of data.

The liquids to be measured were condensates of the saturated hydrocarbon series, mainly pentane and heavier hydrocarbons. Some contained butane. The vapor pressure of the liquid measured in series 2 was approximately a meter at the observed temperatures.

It will be noted from a study of the data presented that the burette is capable of determining liquid volumes to within $0.001 \mathrm{cc}$.

\footnotetext{
a The data here reported were obtained by reading an average temperature, in the event temperature changes occurred during the period of one measurement. A better technic would be to use a properly thermostated bath.

3 Smithsonian Physical Tables, 7th rev. ed., p. 72.
} 


\section{SUMMARY}

A burette has been designed for the micromeasurement of liquid volumes. The principle employed is the measurement of volume by determining the weight of mercury used to displace the liquid to be measured. This is done in such a manner as to eliminate errors of adhesion of the liquid to the glass walls of the burette. Liquids to be measured are transferred to the burette by condensing at liquid air temperatures. The method is applicable to liquids which do not attack mercury and which possess vapor pressures which are not excessive at ordinary room temperatures. It is accurate to within $0.001 \mathrm{cc}$.

\section{TABLe of Results}

Measurements of the liquid volumes of various saturated hydrocarbon condensates

\begin{tabular}{|c|c|c|c|c|c|c|}
\hline Temperature $\left({ }^{\circ} \mathrm{C}.\right)$ & $\begin{array}{l}\text { Weight of } \\
\text { mercury re- } \\
\text { maining in } \\
\text { bulb } 8\end{array}$ & $\begin{array}{l}\text { (See Smith- } \\
\text { sonian Tables, } \\
\text { p. } 72 .) \text { Factor } \\
\text { to correct } \\
\text { weight mer- } \\
\text { cury to cubic } \\
\text { centimeters } \\
\text { at } 20^{\circ} \mathrm{C} \text {. ac- } \\
\text { counting for } \\
\text { cubical expan- } \\
\text { sion of glass } \\
\text { and mercury } \\
\text { with tempera- } \\
\text { ture and } \\
\text { weights in } \\
\text { vacuo }\end{array}$ & $\begin{array}{l}\text { Volume of } \\
\text { mercury } \\
\text { remaining } \\
\text { in bulb } 8\end{array}$ & $\begin{array}{l}\text { Volume of } \\
\text { bulb } 8 \text { less } \\
\text { volume of } \\
\text { mercury } \\
\text { remaining } \\
\text { in bulb } 8 \\
=\text { volume } \\
\text { transferred } \\
\text { to bulb } 12\end{array}$ & $\begin{array}{l}\text { Volume of } \\
\text { bulb } 12 \text { less } \\
\text { volume } \\
\text { transferred } \\
\text { to bulb } 12 \\
=\text { volume } \\
\text { of liquid } \\
\text { under in- } \\
\text { vestigation }\end{array}$ & $\begin{array}{l}\text { Deviation } \\
\text { from } \\
\text { average } \\
\text { volume }\end{array}$ \\
\hline & \multicolumn{4}{|c|}{ SERIES 11} & \multicolumn{2}{|r|}{$\overline{x+2}$} \\
\hline \multirow{2}{*}{$\begin{array}{l}21.9 \\
21.65 \\
22.4 \\
22.2 \\
22.9 \\
\end{array}$} & $\begin{array}{c}{ }^{g} \\
385.257 \\
385.285 \\
385.245 \\
385.241 \\
385.210\end{array}$ & $\begin{array}{l}0.0738392 \\
.0738363 \\
.0738449 \\
.0738426 \\
.0738507\end{array}$ & $\begin{array}{c}c c \\
28.447 \\
28.448 \\
28.448 \\
28.447 \\
28.448\end{array}$ & $\begin{array}{c}c c \\
29.525 \\
29.524 \\
29.524 \\
29.525 \\
29.524\end{array}$ & $\begin{array}{c}c c \\
0.121 \\
.122 \\
.122 \\
.121 \\
.122\end{array}$ & $\begin{array}{c}c c \\
-0.0006 \\
+.0004 \\
+.0004 \\
-.0006 \\
+.0004\end{array}$ \\
\hline & $\begin{array}{r}\text { 14. } 082 \\
\text { 14. } 096 \\
\text { 14. } 077 \\
14.080 \\
14.077\end{array}$ & $\begin{array}{r}0.0738541 \\
.0738622 \\
.0738564 \\
.0738587 \\
.0738599\end{array}$ & $\begin{array}{l}1.040 \\
1.041 \\
1.040 \\
1.040 \\
1.041\end{array}$ & $\begin{array}{l}27.946 \\
27.945 \\
27.946 \\
27.946 \\
27.945\end{array}$ & $\begin{array}{l}1.701 \\
1.702 \\
1.701 \\
1.701 \\
1.702\end{array}$ & $\begin{array}{r}-0.0005 \\
+.0005 \\
-.0005 \\
-.0005 \\
+.0005\end{array}$ \\
\hline & \multicolumn{4}{|c|}{ SERIES 3} & & \\
\hline $\begin{array}{l}23.1 \\
23.3 \\
23.7 \\
23.6 \\
24.0\end{array}$ & $\begin{array}{l}122.689 \\
122.688 \\
122.686 \\
122.687 \\
122.683\end{array}$ & $\begin{array}{l}0.0738530 \\
.0738553 \\
.0738599 \\
.0738587 \\
.0738633\end{array}$ & $\begin{array}{l}\text { 9. } 061 \\
9.061 \\
9.062 \\
9.062 \\
9.062\end{array}$ & $\begin{array}{l}19.925 \\
19.925 \\
19.924 \\
19.924 \\
19.924\end{array}$ & $\begin{array}{l}9.722 \\
9.722 \\
9.723 \\
9.723 \\
9.723\end{array}$ & $\begin{array}{r}-0.0006 \\
+.0006 \\
+.0004 \\
+.0004 \\
+.0004\end{array}$ \\
\hline
\end{tabular}

1 It should be explained that the two bulbs here used were so blown that their calibrated volumes between etch marks happened to be 29.6465 and $28.9860 \mathrm{cc}$. An error in assembly of the apparatus resulted in the placing of the $28.9860 \mathrm{cc}$ bulb as the upper or number 8 of the sketch. This mistake resulted in a necessary double measurement in the event that the liquid volume to be measured was less than the difference $29.6465-28.9860$. That is, bulb 8 must then be filled and entirely discharged into bulb 12, and subsequently refilled and partially discharged, the excess from the second filling being weighed and its difference from twice the volume of 8 taken. Such a case occurs in series 1 of the data, where two chances for error in adjusting mercury meniscus to etch marks 7 and 10 occurred for each volume determined. The results were actually not affected within the limits of error of the apparatus and method.

Washington, February 4, 1927. 